\title{
Compassionate drug (mis)use during pandemics: lessons for COVID-19 from 2009
}

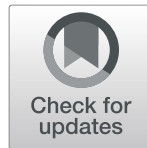

Amanda M. Rojek ${ }^{1,2,3^{*}}$ (D), Genevieve E. Martin ${ }^{4}$ and Peter W. Horby ${ }^{1 *}$

\begin{abstract}
Background: New emerging infections have no known treatment. Assessing potential drugs for safety and efficacy enables clinicians to make evidence-based treatment decisions and contributes to overall outbreak control. However, it is difficult to launch clinical trials in the unpredictable environment of an outbreak. We conducted a bibliometric systematic review for the 2009 influenza pandemic to determine the speed and quality of evidence generation for treatments. This informs approaches to high-quality evidence generation in this and future pandemics.

Methods: We searched PubMed for all clinical data (including clinical trial, observational and case series) describing treatment for patients with influenza A(H1N1)pdm09 and ClinicalTrials.gov for research that aimed to enrol patients with the disease.

Results: Thirty-three thousand eight hundred sixty-nine treatment courses for patients hospitalised with A(H1N1)pdm09 were detailed in 160 publications. Most were retrospective observational studies or case series. Five hundred ninety-two patients received treatment (or placebo) as participants in a registered interventional clinical trial with results publicly available. None of these registered trial results was available during the timeframe of the pandemic, and the median date of publication was 213 days after the Public Health Emergency of International Concern ended.

Conclusion: Patients were frequently treated for pandemic influenza with drugs not registered for this indication, but rarely under circumstances of high-quality data capture. The result was a reliance on use under compassionate circumstances, resulting in continued uncertainty regarding the potential benefits and harms of anti-viral treatment. Rapid scaling of clinical trials is critical for generating a quality evidence base during pandemics.
\end{abstract}

Keywords: Pandemic, Clinical trial, Influenza, H1N1, Systematic review

\footnotetext{
* Correspondence: amanda.rojek@mh.org.au; amanda.rojek@unimelb.edu.au; peter.horby@ndm.ox.ac.uk

'Epidemic Diseases Research Group Oxford (ERGO), Centre for Tropical

Medicine and Global Health, Nuffield Department of Medicine, University of Oxford, Old Road Campus, Roosevelt Drive, Oxford OX3 7FZ, UK

Full list of author information is available at the end of the article
}

(c) The Author(s). 2020 Open Access This article is licensed under a Creative Commons Attribution 4.0 International License, which permits use, sharing, adaptation, distribution and reproduction in any medium or format, as long as you give appropriate credit to the original author(s) and the source, provide a link to the Creative Commons licence, and indicate if changes were made. The images or other third party material in this article are included in the article's Creative Commons licence, unless indicated otherwise in a credit line to the material. If material is not included in the article's Creative Commons licence and your intended use is not permitted by statutory regulation or exceeds the permitted use, you will need to obtain permission directly from the copyright holder. To view a copy of this licence, visit http://creativecommons.org/licenses/by/4.0/ The Creative Commons Public Domain Dedication waiver (http://creativecommons.org/publicdomain/zero/1.0/) applies to the data made available in this article, unless otherwise stated in a credit line to the data. 


\section{Background}

Viral pandemics constitute a major threat to global health security. Future influenza pandemics are considered likely. In the past 20 years, we have also seen the emergence of zoonotic human respiratory coronaviruses with pandemic potential. These have been severe acute respiratory virus (SARS; caused by SARS-CoV-1), Middle East respiratory syndrome (MERS) and, currently, coronavirus disease 2019 (COVID-19) (caused by SARS-CoV-2) [1]. A study of the $2009 \mathrm{H} 1 \mathrm{~N} 1$ strain influenza A (A(H1N1)pdm09) pandemic, the largest respiratory viral outbreak in recent years, can provide insights into the research processes during a pandemic, with the aim of improving these for other outbreaks, including COVID-19.

One important element of pandemic mitigation is prophylaxis and treatment of patients. For emerging viral infections, antiviral therapies are a key medical countermeasure because vaccine production takes months or years, whereas effective antiviral medications may already exist. For COVID-19, the potential of several existing medications (including remdesivir, lopinavir/ritonavir, hydroxychloroquine and tocilizumab) is of interest. During the influenza $\mathrm{A}(\mathrm{H} 1 \mathrm{~N} 1)$ pdm09 pandemic, there was interest in neuraminidase inhibitors (NAIs) as anti-influenza agents, although adequate safety and efficacy data supporting their use were lacking. This evidence has now substantially strengthened [2]; however, much of this was generated after the pandemic. There has been no quantitative assessment of the volume and quality of information that is produced regarding treatments during the pandemic period. This data is important, because it represents what is available to clinicians making treatment decisions for patients under conditions of significant uncertainty [3], and during surging patient numbers [4].
The objective of this systematic review is to investigate how data for drug treatments of $\mathrm{A}(\mathrm{H} 1 \mathrm{~N} 1) \mathrm{pdm} 09$ accrued during the pandemic (detailed objectives listed in Table 1). This review is not only limited to completed clinical trials, but also includes registered trials which were not completed, and reports of treatment outside a formal trial setting (case studies or series and observational studies). These are included as they may represent both the best quality evidence available at the time and also opportunities lost to gather high-quality evidence.

\section{Methods}

We conducted a systematic search to identify patients treated for $\mathrm{A}(\mathrm{H} 1 \mathrm{~N} 1) \mathrm{pdm} 09$ during the pandemic. We searched two types of evidence: peer-reviewed publications and clinical trial registration records. An experienced librarian advised on the search strategy. We prospectively registered the review (PROSPERO database record CRD42016039549). Details of compliance to MOOSE and PRISMA guidelines are found in Additional file 1: appendix 1.

\section{Published literature search}

We searched the PubMed database according to the search strategy found in Additional file 1: appendix 2. To capture information on how many patients received treatment outside of a trial, we included case studies, case series and observational research in addition to interventional research. The single exception was to limit descriptions of the use of oseltamivir to publications with ten or more patients, because case reports were abundant. We included research that described hospitalised patients and reported acute clinical outcomes (defined as the length of hospitalisation, intensive care admission or length of stay, medical complication,

Table 1 Detailed objectives and rationale with respect to evidence generation during a pandemic

Aim
byantify the volume of data that described patient treatment, stratified
by rearch

Document the time taken to initiate and complete this clinical research and compare this to the outbreak epidemiology

\footnotetext{
Document the time taken to submit and publish this research and compare this to the outbreak epidemiology
}

\footnotetext{
Describe the extent to which manuscripts report key clinical parameters, including those needed for stratification of treatment effect (the age of patients, the pregnancy status of patients) or indicate the quality of reporting of treatment effect (adverse events due to treatment)
}

Describe the outcomes of clinical research that was prospectively registered

\section{Reason}

The volume of research gives an indication of the scale of the response mounted. Comparisons of different types of research (clinical trial, hypothesis-driven observational study, case series) describe the quality of evidence available

The faster that clinical research is commenced, the greater the pool of potential participants, and the greater the likelihood of enrolling a sufficient sample size and completing within the timeframe of the outbreak

Research can only influence patient treatment in the current outbreak by providing enhanced evidence if it is available to clinicians treating patients within the time-frame of the outbreak

We have selected key parameters for assessment that would be necessary to know in order to evaluate a treatment effect.

This expands discussion around limits to conducting high-quality research as we can comment on the proportion of planned research that was able to complete. 
requirement for mechanical ventilation or mortality). We included patients with only laboratory-confirmed disease. While $\mathrm{A}(\mathrm{H} 1 \mathrm{~N} 1) \mathrm{pdm} 09$ was the prevailing strain during the outbreak, inconsistencies in defining probable cases between papers meant a consistent inclusion method was not possible. We included papers only if enrolment opened between April 1, 2009 (when the virus strain was first identified), and was completed by August 10, 2010 (the declaration of the end of the Public Health Emergency of International Concern [PHEIC]), by the World Health Organization (WHO). This limitation was necessary to differentiate research conducted specifically for the pandemic, compared with routine seasonal influenza reporting once $\mathrm{A}(\mathrm{H} 1 \mathrm{~N} 1)$ pdm09 became a seasonal strain. These criteria did not apply for clinical trials (where there could be no confusion with seasonal reporting).

We excluded papers if the description of treatment was not quantifiable or the treatment name was absent (including use of the general term 'antiviral therapy'). We defined treatment as pathogen-directed therapy (e.g. antivirals) or host-directed therapy where there was a specific indication for $\mathrm{A}(\mathrm{H} 1 \mathrm{~N} 1)$ pdm09. We therefore excluded descriptions of standard intensive care interventions including corticosteroids and extracorporeal membrane oxygenation. When a single patient cohort (same sample size, enrolment period, author(s) and study location) was presented in more than one paper, duplicates were excluded. We excluded languages other than English.

\section{Clinical trial registry search}

We undertook two clinical trial registry searches. The purpose of the first was to examine research that was planned in response to the pandemic. ClinicalTrials.gov was searched using the condition ' $\mathrm{H} 1 \mathrm{N1}$ ' and dates were restricted to limit to registration dates following the onset of the pandemic. A second search was conducted to identify pre-existing influenza studies that were able to enrol A(H1N1)pdm09-infected patients. ClinicalTrials.gov was searched using the condition 'influenza'. Detailed inclusion and exclusion criteria and subgroup analysis plans for both searches are contained in Additional file 1: appendix 3.

\section{Data extraction}

One reviewer (AR) undertook data extraction according to the pre-specified inclusion and exclusion criteria. Decisions were recorded using electronic systematic review software (Rayyan [5]), available to the senior author (PWH). We did not request missing data from authors, as this does not contribute to the aims of this review. Details of the data extracted are in Additional file 1: appendix 3.

\section{Statistical analysis}

Descriptive statistics are presented as frequencies for categorical variables and median with interquartile range for continuous variables. The findings from published literature and trial registries are reported separately. Analysis of the literature was stratified by research type. Chinese medicines are presented as a single class because individual components could not be differentiated. Assessment of combination therapy was not possible due to variable reporting practices in the literature. Stata MP/15.0 and Microsoft Excel for Mac/15.21.1 were used for statistical analysis and graphical depiction.

\section{Role of the funding source}

The funder of the study had no role in study design, data collection, data analysis, data interpretation or writing of the report.

\section{Results}

\section{Findings from published literature}

This review includes 160 papers (summarised in Fig. 1, details in Additional file 1: appendix 4) that describe 39, 577 hospitalised patients with $\mathrm{A}(\mathrm{H} 1 \mathrm{~N} 1) \mathrm{pdm} 09$ and 33, 869 treatment courses (Table 2). Twelve different treatments were used, with oseltamivir being the most common (Table 2). The median number of treatments described per manuscript is 63 (interquartile range, IQR 22-193). Of the 160 papers included, two are interventional trials $(n=73$, representing $0.2 \%$ of total reported patients), [6, 7] 28 are prospective observational studies ( $n=6102$, accounting for $15.4 \%$ of total patients), 129 are retrospective observational studies or case reports ( $n=33,342,84.2 \%$ of total patients) and one enrolled patients both prospectively and retrospectively $(n=98$, $0.2 \%$ of patients).

Early initiation of prospective research maximises the probability of meeting sample size targets before an outbreak wanes. The median delay to first patient enrolment since the identification of the pandemic viral strain (April 1, 2009) for prospective observational studies was 102 days (IQR 61-172 days). The two clinical trials began enrolment after a delay of 244 and 275 days.

For prospective observational studies, enrolment stopped a median of 274 (IQR 195-313) days after viral identification. This was 223 days before the PHEIC ended (August 10, 2010), but when case numbers were falling. The two clinical trials closed enrolment 699 and 944 days after virus identification (March and November 2011).

The publication dates of all articles over time are shown in Fig. 2. No (0/2) interventional trials were published before the end of the PHEIC. Twenty-five per cent (7/28) of prospective observational studies and 22\% (28/ 130) of retrospective or mixed-enrolment research were 


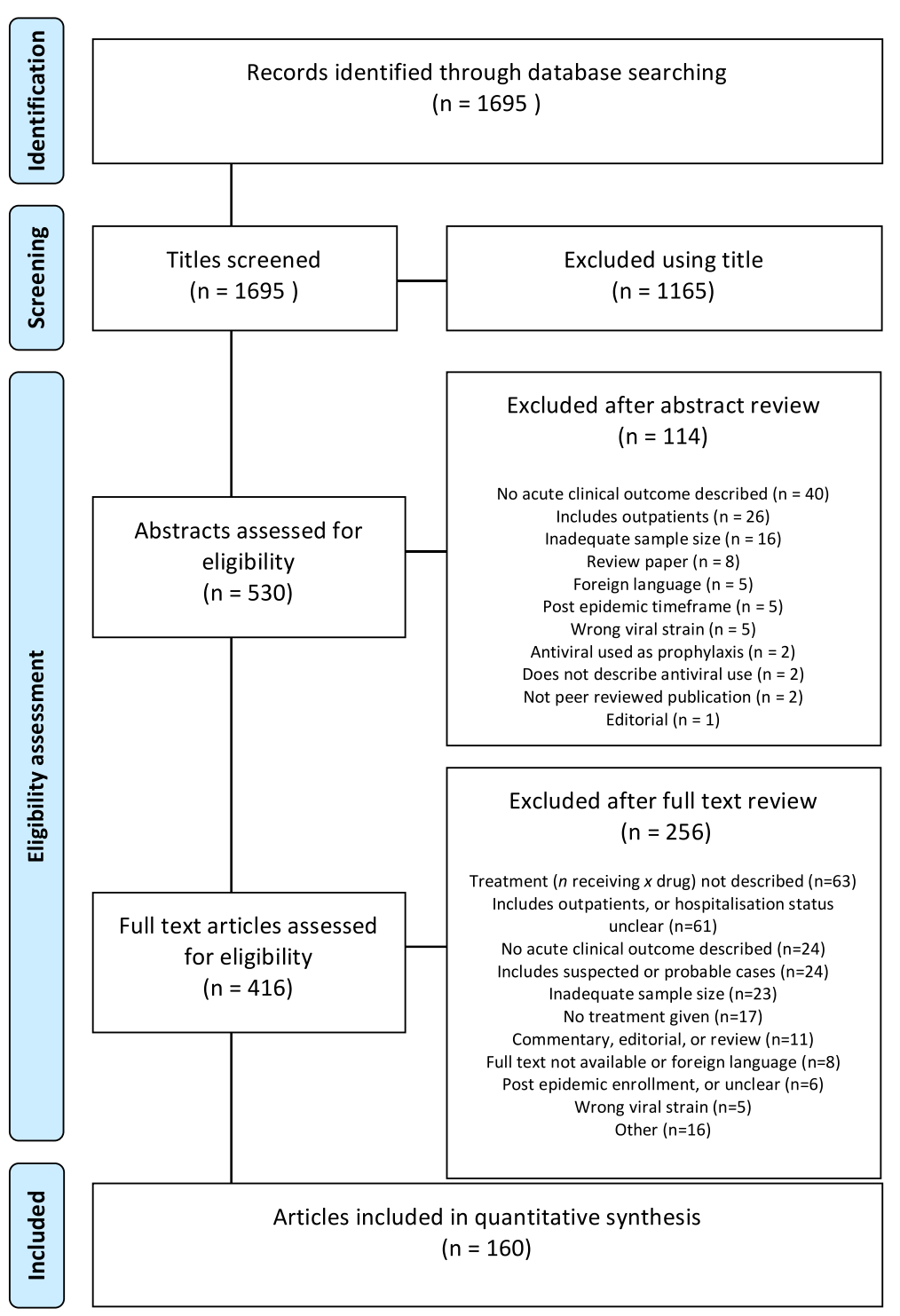

Fig. 1 Study selection

published by the end of the PHEIC. The median date of publication for all papers was March 18, 2011 (IQR September 28, 2010, to October 24, 2011); this was 213 days after the PHEIC ended. Overall, the median delay between final patient enrolment (or inclusion) and date of publication was 444 days (IQR 281-684). The median date between final patient enrolment and submission was 302 days (IQR 142-534), between submission and acceptance 93 days (IQR 63-144), and acceptance to publication was 56 days (IQR 24-94) where data existed for these intervals.

Thirty-nine countries reported treatment data. The highest number of papers was published by the USA ( $n=25$, reporting 2559 treatment courses), followed by China ( $n=16$, reporting 14,680 treatment courses) and Spain ( $n=16$, reporting 4103 treatment courses).
Country-level data describing the number of publications and treatment courses described and the first date of patient enrolment in prospective research (where relevant) are shown in Additional file 1: appendix 5).

Articles described the pregnancy status of patients in $88 \%(140 / 160)$ of articles. Articles described the inclusion of elderly patients in $88 \%(140 / 160)$ of articles and children in $93 \%(149 / 160)$ of articles.

Twenty-three per cent (36/160) of papers described adverse effects from treatment had occurred. In $42 \%$ of cases, adverse effects or severe adverse events were noted. Thirteen per cent (21/159) of articles tested for resistance and described some resistant samples, 4\% (6/ 159) of articles tested for resistance but found no mutations, 3\% (5/159) of articles reported clinical suspicion of antiviral resistance and, in the remaining 81\% (129/159) 
Table 2 Volume of treatment courses described in the literature for hospitalised patients

\begin{tabular}{|c|c|c|c|c|}
\hline Treatment name & $\begin{array}{l}\text { Number of } \\
\text { publications } \\
\text { reporting use }\end{array}$ & $\begin{array}{l}\text { Total number of } \\
\text { patients receiving } \\
\text { treatment }^{1}\end{array}$ & $\begin{array}{l}\text { Median (IQR) number of patients } \\
\text { receiving treatment per } \\
\text { publication }{ }^{2}\end{array}$ & $\begin{array}{l}\text { FDA drug approval status for use in influenza } \\
\text { in } 2009\end{array}$ \\
\hline Oseltamivir & 154 & 31,737 & $63(21-188)$ & $\begin{array}{l}\text { Approved for acute uncomplicated influenza, } \\
\text { expanded under EUA April } 2009\end{array}$ \\
\hline Zanamivir & 54 & 368 & $2(1-9)$ & $\begin{array}{l}\text { Approved for acute uncomplicated influenza, } \\
\text { expanded under EUA April } 2009\end{array}$ \\
\hline Peramivir & 14 & 403 & $1(1-3)$ & $\begin{array}{l}\text { Unapproved, elND in April 2009, EUA October } \\
2009\end{array}$ \\
\hline Amantadine & 11 & 86 & $3(1-13)$ & $\begin{array}{l}\text { Approved for acute uncomplicated influenza, } \\
\text { but resistance to } A(\mathrm{H} 1 \mathrm{~N} 1) \text { pdm09 demonstrated }\end{array}$ \\
\hline Rimantadine & 5 & 32 & $3(1-13)$ & $\begin{array}{l}\text { Approved for acute uncomplicated influenza, } \\
\text { but resistance to } A(\mathrm{H} 1 \mathrm{~N} 1) \text { pdm09 demonstrated }\end{array}$ \\
\hline Ribavirin & 5 & 34 & $2(1-6)$ & Not approved for influenza \\
\hline $\begin{array}{l}\text { Intravenous } \\
\text { immunoglobulin }\end{array}$ & 4 & 44 & $4(2-20)$ & Not approved for influenza \\
\hline $\begin{array}{l}\text { Chinese } \\
\text { medicines }\end{array}$ & 3 & 1051 & $245(56-750)$ & Not approved for influenza \\
\hline $\begin{array}{l}\text { Convalescent } \\
\text { Plasma }\end{array}$ & 2 & 52 & 26 & Not approved for influenza \\
\hline Macrolides $^{3}$ & 1 & 31 & 31 & Not approved for influenza \\
\hline Sirolimus & 1 & 19 & 19 & Not approved for influenza \\
\hline Statins $^{3}$ & 1 & 12 & 12 & Not approved for influenza \\
\hline
\end{tabular}

Volume of treatment courses described in the literature for hospitalised patients with $2009 \mathrm{H} 1 \mathrm{~N} 1$ influenza during the pandemic period eIND emergency investigational new drug authorisation, EUA emergency use authorization

'Some patients received more than one treatment

${ }^{2}$ When publication describes use of that drug

${ }^{3}$ Where clear indication was influenza

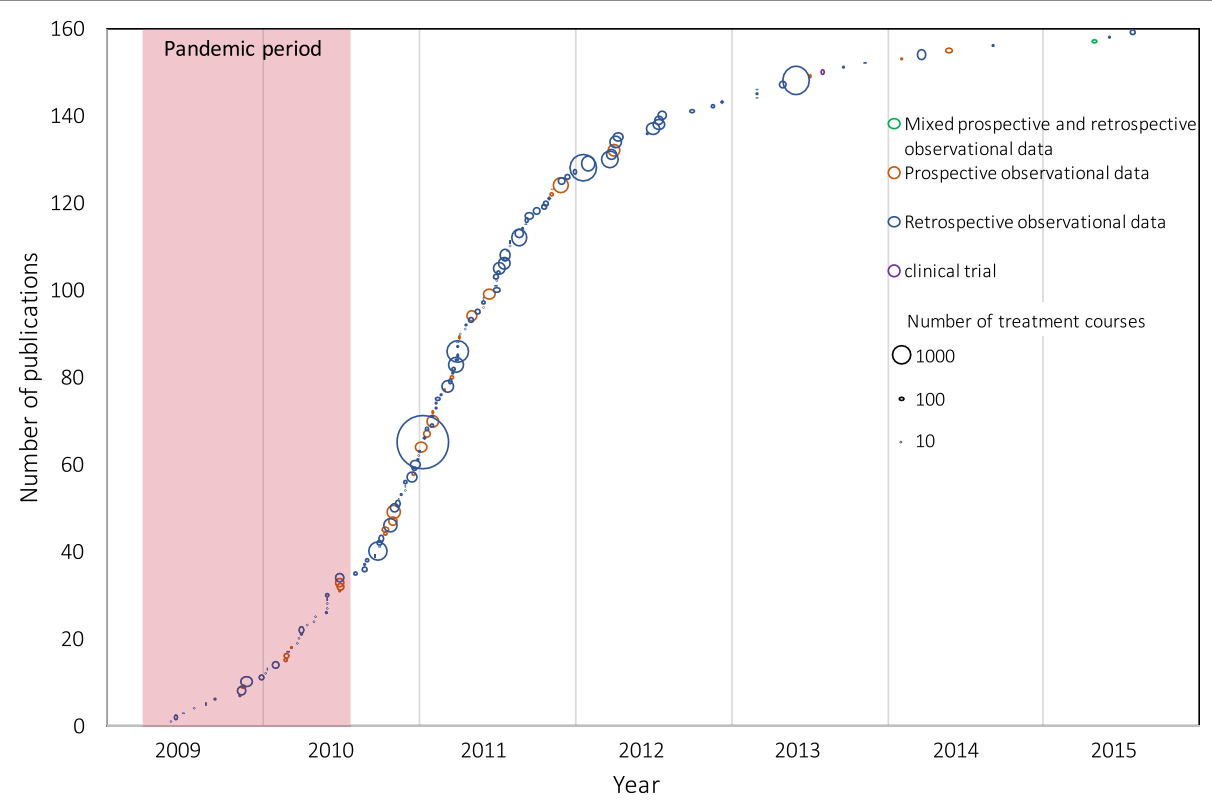

Fig. 2 Publication of included studies over time. Studies are shown according to the type of the study and the number of treatment courses described. The pandemic period ranges from the 1st of April 2009 to the end of the PHEIC on 10th of August 2009 
of papers, there was no statement regarding antiviral resistance; one paper described no antiviral use and was excluded.

\section{Findings from $\mathrm{H} 1 \mathrm{~N} 1$ trial registrations}

Fifteen H1N1 study registration records were included in the review (Additional file 1: appendix 6) comprising 10 interventional trials and 5 observational studies (2 with treatment efficacy outcomes, and 3 with general acute clinical outcomes) planned during the pandemic. A total of eight different treatments were to be studied: oseltamivir, zanamivir, convalescent plasma, intravenous immunoglobulin, rosuvastatin, sirolimus, Chinese herbs and vitamin supplementation (vitamins $\mathrm{A}, \mathrm{C}$ and $\mathrm{E}$ ).

Of the 15 studies, nine are reported as completed, four were terminated due to the end of the H1N1 pandemic or declining case numbers and the status of two studies is not recorded. The anticipated and actual enrolment of patients into all studies is depicted in Fig. 3. Some study protocols excluded patients because of young age (25\%) and pregnancy (50\%). Results are available in the literature for three of the completed studies (Fig. 3), representing 153 patients, and available on the clinical trials registry for an additional two of the terminated studies. A sub-group analysis of clinical trials that only included hospitalised or severe cases is provided in Additional file 1: appendix 7.

\section{Findings from influenza trial registration}

Eighteen influenza registration records were reviewed (Additional file 1: appendix 8). There were 16 interventional trials and two observational studies that were enrolling patients during the $\mathrm{A}(\mathrm{H} 1 \mathrm{~N} 1) \mathrm{pdm} 09$ pandemic period. The treatments under investigation were oseltamivir, sambucol supplement, zanamivir, peramivir, amantadine, pomegranate supplement, nitazoxanide and favipiravir.

Eleven studies were completed, four were terminated early, the status of two is unknown and one study has ongoing enrolment listed. Results were available for nine of 11 completed studies (Table 3), representing 439 $\mathrm{A}(\mathrm{H} 1 \mathrm{~N} 1) \mathrm{pdm} 09$ patients.

\section{Discussion}

There is consistent criticism that the research response to disease outbreaks is fractured and delayed [13-15].

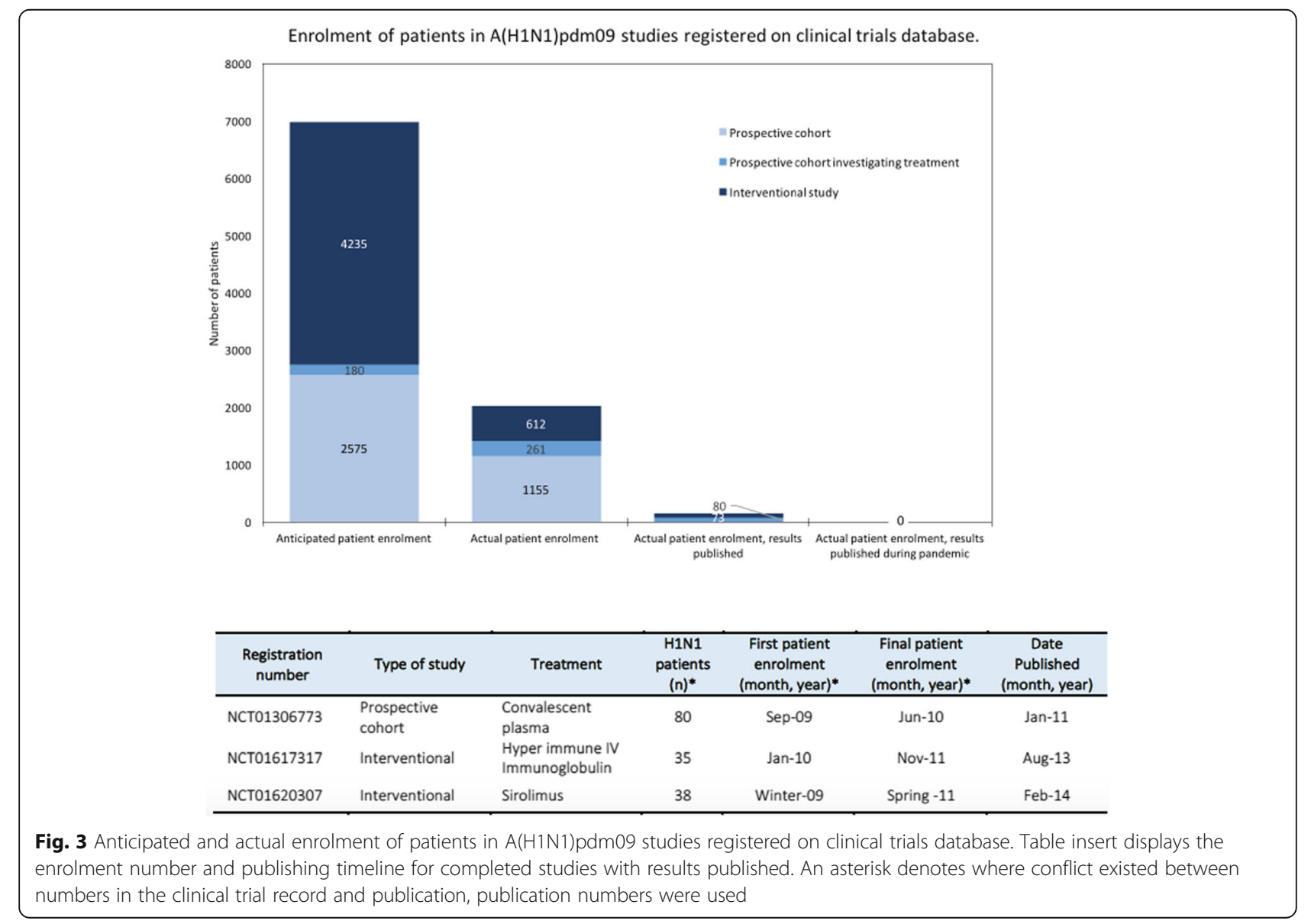


Table 3 Enrolment number and publishing timeline for completed studies

\begin{tabular}{|c|c|c|c|c|c|c|c|c|}
\hline Registration number & Type of study & Treatment & $\begin{array}{l}\text { Planned } \\
\text { enrolment } \\
\text { (n) } \\
\end{array}$ & $\begin{array}{l}\text { Total } \\
\text { patients } \\
(\boldsymbol{n}) \\
\end{array}$ & $\begin{array}{l}\text { H1N1 } \\
\text { patients } \\
(\boldsymbol{n})\end{array}$ & $\begin{array}{l}\text { First patient } \\
\text { enrolment }{ }^{1} \\
\text { (month, year) }\end{array}$ & $\begin{array}{l}\text { Last patient } \\
\text { enrolment }{ }^{1} \\
\text { (month, year) }\end{array}$ & $\begin{array}{l}\text { Date published } \\
\text { (month, year) }\end{array}$ \\
\hline \multicolumn{9}{|c|}{ Enrolment commenced before pandemic } \\
\hline NCT00298233 & Phase 2 & Oseltamivir & 400 & 326 & 72 & Apr. 2007 & Feb. 2010 & May 2013 [8] \\
\hline NCT00391768 & Phase $1 / 2$ & Oseltamivir & 108 & 87 & 37 & Jan. 2007 & Apr. 2010 & Mar. 2013 [9] \\
\hline \multicolumn{9}{|c|}{ Enrolment commenced during pandemic } \\
\hline NCT00949533 & Phase 3 & Oseltamivir & 125 & 37 & Unknown & Aug. 2009 & Oct. 2010 & Apr. 2016 (Unp) \\
\hline NCT00957996 & Phase 3 & Peramivir & 300 & 127 & 94 & Oct. 2009 & Oct. 2010 & Aug. 2013 [10] \\
\hline NCT01199744 & $\begin{array}{l}\text { Prospective } \\
\text { cohort }\end{array}$ & Zanamivir & $N / R$ & 1575 & Unknown & Nov. 2009 & Apr. 2010 & Mar. 2011(Unp) \\
\hline NCT01014988 & Phase 2 & Zanamivir & 150 & 130 & 92 & Nov. 2009 & Sep. 2011 & Feb. 2014 [11] \\
\hline NCT01052961 & Phase 4 & Oseltamivir & 400 & 155 & 34 & Jan. 2010 & Jun. 2012 & Dec. 2013 [12] \\
\hline NCT01050257 & Phase 3 & Oseltamivir & 200 & 118 & Unknown & Jan. 2010 & Sep. 2012 & Aug. 2013 (Unp) \\
\hline NCT01068912 & Phase 2 & Favipiravir & 384 & 530 & 110 & Feb. 2010 & May 2012 & Feb. 2014 (Unp) \\
\hline
\end{tabular}

Enrolment number and publishing timeline for completed studies where results are published in the literature (date followed by reference) or on the clinical trials registration site (date followed by Unp)

$N / R$ not reported

${ }^{1}$ Where conflict existed between numbers in the clinical trial record and publication, publication numbers were used

There has, however, been little quantitative examination of these assumed insufficiencies. This paper demonstrates that despite over 33,000 treatment courses being described for hospitalised patients with influenza $\mathrm{A}(\mathrm{H} 1 \mathrm{~N} 1) \mathrm{pdm} 09$ during the pandemic, fewer than 600 received treatment (or placebo) as participants in a registered interventional clinical trial with results available in the peer-reviewed literature. None of these registered trial results was available during the timeframe of the pandemic, as were few of the findings from observational studies. This constitutes a significant failure to collect high-quality data.

Our findings demonstrate that we must make improvements in order to offer patients, and their treating clinicians, evidence-based care during pandemics, including the COVID-19 pandemic. Several drugs are being investigated as potential treatment for COVID19 , but we note that some early published studies were poorly controlled $[16,17]$. It is imperative that we learn from the $\mathrm{A}(\mathrm{H} 1 \mathrm{~N} 1) \mathrm{pdm} 09$ pandemic and ensure that trials of therapeutics are done under conditions which allow for the collection of high-quality, interpretable data to inform future clinical care.

We found that most descriptions of treatment courses were in retrospective observational studies or case series, with few prospective studies launched. There was relative success, however, in enrolling $\mathrm{A}(\mathrm{H} 1 \mathrm{~N} 1) \mathrm{pdm} 09$ patients in ongoing or seasonal influenza studies-of the 582 patients enrolled in a trial, 439 were enrolled in this manner. Indeed, conducting trials of therapeutics for similar diseases (such as seasonal influenza) during an inter-epidemic period has been proposed as a solution to improving the outbreak research response [18]. This occurs not only by allowing the rapid recruitment of individuals in the case of an outbreak (as was observed here) but also by testing trial design and establishing research capacity. Novel trial designs, such as adaptive, platform trials, should also be adopted as a way to expedite outbreak research [18]. Using this approach, multiple treatments (or even multiple respiratory viruses) can be evaluated under an overarching protocol and regulatory framework, improving efficiency [19]. Findings presented here from 2009 support the need for this approach to respiratory virus pandemics, including COVID-19. Indeed, two large platform trials for therapeutics in COVID-19 are underway (RECOVERY [ISRCTN50189673] and Solidarity [ISRCTN83971151]) and already generating high-quality evidence [20]. Sleeper protocol research may provide a further solution. These pre-prepared and pre-approved protocols can lay dormant, waiting for cases of pandemic respiratory viruses, and allow prior assessment of the logistics and feasibility of the protocol. An example of this type of protocol exists for severe acute respiratory infections (NCT02498587) and has been used to rapidly enrol patients with COVID- 19 .

Recommendations following the Ebola virus disease (EVD) epidemic in West Africa suggest that clinical research should be initiated, enacted and completed by the 
time an epidemic peaks [21]. We found that from the time influenza $\mathrm{A}(\mathrm{H} 1 \mathrm{~N} 1) \mathrm{pdm} 09$ was first detected, it was over 3 months before prospective data collection began and 8 months before the first interventional trial began recruitment. While these delays compare well to recent evaluations of delays for other epidemic observational research [22] or clinical trials [23], it remains too slow.

Additionally, the small sample sizes of literature included in our review indicate a fractured research response. It has been estimated that a sample size of 800 patients is required to power a randomised controlled trial of an NAI in hospitalised patients [24]. No prospective research identified here was that large. Beyond the benefits of increased enrolment and external validity, multicentre research has specific advantages in epidemics. It can compensate for unexpected variations in epidemiology at the regional level (such as the sudden end to the EVD outbreak in Liberia that prematurely halted a clinical treatment trial) [25] or the temporary closure of health care facilities with nosocomial transmission (such as occurred during the SARS outbreak of 2003) [26].

To ensure generalisability of findings, research responses to outbreaks should also be representative of geographic diversity and global epidemiology. In the results reported here, China was heavily represented and reported the majority of treatment courses described $(14,680 ; 43.3 \%$ of the total). Patient characteristics (including age, gender and other risk factors) and healthcare systems vary substantially by country/ region, with likely impacts on the suitability and relative efficacy of interventions in these different settings. A timely research response from one region will not necessarily be of benefit to the majority of the global at-risk population, particularly if low- and middle-income countries (LMICs) are poorly represented in the epidemic evidence base. Indeed, the importance of strengthening the research capacity and infrastructure of LMICs to enable effective outbreak responses was highlighted following the EVD epidemic $[21,27]$.

The inclusion of high-risk groups (such as elderly individuals, pregnant women and children) is also important to ensure generalisability of outbreak research. During the influenza A(H1N1)pdm09 pandemic, elderly and paediatric individuals were included in 88 and $93 \%$ of publications, respectively, noting again that the vast majority of these studies were observational only. At the onset of the pandemic, however, trials for approved neuraminidase inhibitors had only been conducted for mild seasonal influenza in healthy adults [28], without the inclusion of those highest at risk. A failure to include high-risk groups in initial prospective trials for novel medications may further delay the evidence base for these individuals when drugs are employed under outbreak circumstances.

We report long delays between clinical data capture and publication in the peer-reviewed literature. This is consistent with analyses for other disease outbreaks, including epidemiology reporting for SARS (where only $7 \%$ of articles were published within the timeframe of the epidemic) [29] and randomised controlled trials of pandemic H1N1 vaccines (where only $29 \%$ of clinical trial results were published almost a year following the end of the pandemic) [30]. The present WHO standard for interventional clinical trials is that main findings are to be submitted for publication within 12 months of study completion [31] and although no such guidelines exist for observational clinical data, there are analogous scientific and ethical imperatives for timely reporting.

While the ramifications of delayed reporting are described for other fields [32], there are specific imperatives for rapid data reporting during epidemics. For example, observational data must be accrued to design interventional trials (such as approximating the type and rate of outcomes). Emerging evidence can also prioritise trials so that the most promising continue recruitment when there are a declining number of cases late during an outbreak [18].

Initiatives to minimise publication delay now include fast-track review for manuscripts likely to change clinical practice [33]; this approach been widely employed by journals during the COVID-19 pandemic. Pre-approval of trial protocols (where some peer-review occurs before a study is conducted) or results-free review (where review excludes results and some discussion) are alternative peerreview models which aim to improve focus on study quality and reduce bias toward publication of only positive findings [34]. These may also have utility in speeding up the dissemination of quality clinical research in the outbreak setting, by allowing for peerreview to begin at the same time as data collection; whether this is the case is yet to be tested. There is also support for pre-publication online release of preliminary findings. Indeed, the increasing utilisation of pre-publication servers (such as medRxiv) has been reflected in the COVID-19 outbreak. Dissemination of research findings via pre-publication (prior to peer-review) reduces delays but carries risks for validation of methodology, accuracy of data and interpretation of findings. The extraordinary number of COVID-19 articles being submitted to prepublication servers [35] has led to several rapid, open, peer-review platforms for COVID-19 preprints being developed [36, 37]. These aim to improve 
quality control in the period between preprint dissemination and the formal peer-review/publication process; such 'overlay' review models are new and how these will impact on the quality of data generation and dissemination is not yet known.

This systematic review has several limitations. The scope of our review was narrowed due to the high volume of clinical literature discussing $A(H 1 N 1) p d m 09$. In particular, we focused only on hospitalised patients where most antivirals were used [38]. There is likely to be considerable geographic variation in what illness severity necessitates hospitalisation which may have limited the inclusion of studies from countries where care models differ (including LMICs). Furthermore, only English language manuscripts were included which may have led to similar bias in included study geography. We included several publication types, including case series or observational studies to provide an estimate of patients who may have been eligible for inclusion in a clinical trial (noting this estimate does not represent the true number of hospitalised patients who were treated). The precision of any estimate is affected by excluding papers where treatment was not clearly defined and when pandemic strain influenza was not laboratory confirmed. Our estimates of patients enrolled in clinical trials is almost certainly an underestimationmuch of the momentum toward compulsory registration of clinical trials [39] occurred subsequent to the pandemic and trials may have been registered elsewhere and so it is likely that other trials were planned, initiated or even completed without public knowledge. We restricted our observational data collection to that captured before the end of the PHEIC, and while we recognise that research continued to occur during the second and third waves of the epidemic, differentiating this work from routine seasonal influenza research became difficult. Finally, there was only one reviewer for pragmatic reasons.

\section{Conclusions}

Here, we demonstrate how tolerance of treatment under compassionate care circumstances during the influenza $\mathrm{A}(\mathrm{H} 1 \mathrm{~N} 1) \mathrm{pdm} 09$ pandemic was not matched with a commitment to capture high-quality data on treatment use and therefore failed the standards expected of modern evidence-based medicine. Moreover, we show that the data that was collected on patients was incompletely reported and published after prolonged delay. We recommend early initiation of multicentre collaborative trials and pre-approved or sleeper protocols as potential solutions to improve accumulation of treatment data during a pandemic.

\section{Supplementary information}

Supplementary information accompanies this paper at https://doi.org/10. 1186/s12916-020-01732-5.

Additional file 1: Appendix 1. Checklist summarising compliance with MOOSE and PRISMA guidelines. Appendix 2. Details of search strategy.

Appendix 3. Details of clinical registry search strategy and data extraction. Appendix 4. Studies included in systematic review. Appendix 5. Country level data demonstrating number of treatment courses described in the literature, and date of first enrolment in prospective research, where relevant. Appendix 6. Prisma flow diagram describing screening, eligibility and inclusion for clinical trial registration records for studies aimed at enrolling $\mathrm{A}(\mathrm{H} 1 \mathrm{~N} 1)$ pdm09 patients.

Appendix 7. Enrolment metrics for studies enrolling A(H1N1)pdm09patients, when analysis is restricted to 'serious' and hospitalized patients. Appendix 8. Prisma flow diagram describing screening, eligibility and inclusion for clinical trial registration records for studies aimed at enrolling influenza patients, that were open during the pandemic period.

\section{Abbreviations}

COVID-19: Coronavirus disease 2019; EVD: Ebola virus disease; IQR: Interquartile range; LMICs: Low- and middle-income countries; MERS: Middle East respiratory syndrome; NAI: Neuraminidase inhibitor; PHEl C: Public Health Emergency of International Concern; SARS: Severe acute respiratory virus; WHO: World Health Organization

\section{Acknowledgments}

Not applicable.

\section{Authors' contributions}

$\mathrm{AR}$ and PH conceived and designed the study and had full access to all data in the study. AR and GM and drafted the manuscript with input from $\mathrm{PH}$. AR carried out the statistical analysis, takes responsibility for the integrity of the data and the accuracy of the data analysis and is the guarantor. All authors have read and approved the final manuscript.

\section{Funding}

This work was supported by the Wellcome Trust [grant numbers 107834/Z/ 15/Z and 106491/Z/14/Z]. AR is supported by Open Philanthropies.

\section{Availability of data and materials}

Details of all studies included in this systematic review are available in Additional file 1: appendix 4. Extracted data are available from the lead author on reasonable request.

Ethics approval and consent to participate Ethics approval was not required for this work.

\section{Consent for publication}

Not applicable.

\section{Competing interests}

We declare one competing interest. We make the case for large-scale harmonised pandemic trials in this manuscript, and the senior author (Peter Horby) is leading the Randomised Evaluation of COVID-19 Therapy (RECOVERY) trial, which is the largest clinical trial for COVID-19 treatments presently enrolling across the UK.

\section{Author details}

${ }^{1}$ Epidemic Diseases Research Group Oxford (ERGO), Centre for Tropical Medicine and Global Health, Nuffield Department of Medicine, University of Oxford, Old Road Campus, Roosevelt Drive, Oxford OX3 7FZ, UK. ${ }^{2}$ Emergency Department, The Royal Melbourne Hospital, Melbourne, Victoria, Australia. ${ }^{3}$ Centre for Integrated Critical Care, University of Melbourne, Melbourne, Victoria, Australia. ${ }^{4}$ Department of Allergy, Immunology and Respiratory Medicine, The Alfred Hospital, Melbourne, Victoria, Australia. 
Received: 11 May 2020 Accepted: 5 August 2020

Published online: 21 August 2020

\section{References}

1. Zhu N, Zhang D, Wang W, Li X, Yang B, Song J, et al. A novel coronavirus from patients with pneumonia in China, 2019. N Engl J Med. 2020;382(8): 727-33.

2. Dobson J, Whitley RJ, Pocock S, Monto AS. Oseltamivir treatment for influenza in adults: a meta-analysis of randomised controlled trials. Lancet. 2015;385(9979):1729-37.

3. Lipsitch M, Riley S, Cauchemez S, Ghani AC, Ferguson NM. Managing and reducing uncertainty in an emerging influenza pandemic. N Engl J Med. 2009:361(2):112-5

4. Wang $\mathrm{XL}$, Wong $\mathrm{CM}$, Chan $\mathrm{KH}$, Chan KP, Cao PH, Peiris JM, et al. Hospitalization risk of the 2009 H1N1 pandemic cases in Hong Kong. BMC Infect Dis. 2014;14:32.

5. Ouzzani M, Hammady H, Fedorowicz Z, Elmagarmid A. Rayyan-a web and mobile app for systematic reviews. Syst Rev. 2016;5(1):210.

6. Hung IF, To KK, Lee CK, Lee KL, Yan WW, Chan K, et al. Hyperimmune IV immunoglobulin treatment: a multicenter double-blind randomized controlled trial for patients with severe 2009 influenza $A(H 1 N 1)$ infection. Chest. 2013;144(2):464-73.

7. Wang CH, Chung FT, Lin SM, Huang SY, Chou CL, Lee KY, et al. Adjuvant treatment with a mammalian target of rapamycin inhibitor, sirolimus, and steroids improves outcomes in patients with severe H1N1 pneumonia and acute respiratory failure. Crit Care Med. 2014;42(2):313-21.

8. South East Asia Infectious Disease Clinical Research N. Effect of double dose oseltamivir on clinical and virological outcomes in children and adults admitted to hospital with severe influenza: double blind randomised controlled trial. BMJ. 2013;346:f3039.

9. Kimberlin DW, Acosta EP, Prichard MN, Sanchez PJ, Ampofo K, Lang D, et al. Oseltamivir pharmacokinetics, dosing, and resistance among children aged $<2$ years with influenza. J Infect Dis. 2013;207(5):709-20.

10. Ison MG, Fraiz J, Heller B, Jauregui L, Mills G, O'Riordan W, et al. Intravenous peramivir for treatment of influenza in hospitalized patients. Antivir Ther. 2014;19(4):349-61.

11. Marty FM, Man CY, van der Horst C, Francois B, Garot D, Manez R, et al. Safety and pharmacokinetics of intravenous zanamivir treatment in hospitalized adults with influenza: an open-label, multicenter, single-arm, phase II study. J Infect Dis. 2014;209(4):542-50.

12. Lee N, Hui DS, Zuo Z, Ngai KL, Lui GC, Wo SK, et al. A prospective intervention study on higher-dose oseltamivir treatment in adults hospitalized with influenza a and B infections. Clin Infect Dis. 2013;57(11):1511-9.

13. Rojek AM, Horby PW. Modernising epidemic science: enabling patientcentred research during epidemics. BMC Med. 2016;14(1):212.

14. Tran TH, Ruiz-Palacios GM, Hayden FG, Farrar J. Patient-oriented pandemic influenza research. Lancet. 2009;373(9681):2085-6.

15. Hayden FG, Farrar J, Peiris JS. Towards improving clinical management of Middle East respiratory syndrome coronavirus infection. Lancet Infect Dis. 2014;14(7):544-6.

16. Grein J, Ohmagari N, Shin D, Diaz G, Asperges E, Castagna A, et al. Compassionate use of remdesivir for patients with severe Covid-19. New England J Med. 2020; [Epub ahead of print].

17. Gautret $\mathrm{P}$, Lagier JC, Parola P, Hoang VT, Meddeb L, Mailhe M, et al. Hydroxychloroquine and azithromycin as a treatment of COVID-19: results of an open-label non-randomized clinical trial. Int J Antimicrob Agents. 2020;105949 [Epub ahead of print].

18. Rojek AM, Horby PW. Offering patients more: how the West Africa Ebola outbreak can shape innovation in therapeutic research for emerging and epidemic infections. Philos Trans R Soc Lond B Biol Sci. 2017;372(1721).

19. Woodcock J, LaVange LM. Master protocols to study multiple therapies, multiple diseases, or both. N Engl J Med. 2017;377(1):62-70

20. Group RC, Horby P, Lim WS, Emberson JR, Mafham M, Bell JL, et al. Dexamethasone in hospitalized patients with Covid-19 - preliminary report. N Engl J Med. 2020.

21. The National Academies Press. Integrating clinical research into epidemic response: the Ebola experience. Washington, DC: The National Academies of Sciences, Engineering, Medicine; 2017.

22. Rishu AH, Marinoff N, Julien L, Dumitrascu M, Marten N, Eggertson S, et al. Time required to initiate outbreak and pandemic observational research. J Crit Care. 2017:40:7-10.
23. Rojek AM, Dunning J, Leliogdowicz A, Castle L, Van Lieshout M, Carson G, et al. Regulatory and operational complexities of conducting a clinical treatment trial during an Ebola virus disease epidemic. Clin Infect Dis. 2018; 66(9):1454-7.

24. Wellcome Trust and The Academy of Medical Sciences. Use of neuraminidase inhibitors in influenza 2015. Available from: https:/acmedsci. ac.uk/file-download/38069-561595082cd83.pdf. Accessed 29 Apr 2020.

25. Dunning J, Kennedy SB, Antierens A, Whitehead J, Ciglenecki I, Carson G, et al. Experimental treatment of Ebola virus disease with brincidofovir. PLoS One. 2016;11(9):e0162199.

26. Cheng VC, Chan JF, To KK, Yuen KY. Clinical management and infection control of SARS: lessons learned. Antivir Res. 2013;100(2):407-19.

27. Kayem ND, Rojek A, Denis E, Salam A, Reis A, Olliaro P, et al. Clinical REsearch during outbreaks (CREDO) training for low- and middle-income countries. Emerg Infect Dis. 2019;25(11):2084-7.

28. Gubareva LV, Kaiser L, Hayden FG. Influenza virus neuraminidase inhibitors. Lancet. 2000;355(9206):827-35.

29. Xing W, Hejblum G, Leung GM, Valleron AJ. Anatomy of the epidemiological literature on the 2003 SARS outbreaks in Hong Kong and Toronto: a time-stratified review. PLoS Med. 2010;7(5):e1000272.

30. Ioannidis JP, Manzoli L, De Vito C, D'Addario M, Villari P. Publication delay of randomized trials on 2009 influenza A (H1N1) vaccination. PLoS One. 2011; 6(12):e28346.

31. World Health Organisation. WHO Statement on Public Disclosure of Clinical Trial Results 2015 [Available from: https:/www.who.int/ictrp/results/WHO_ Statement_results reporting_clinical_trials.pdf?ua=1. Accessed 29 Apr 2020.

32. Moorthy VS, Karam G, Vannice KS, Kieny MP. Rationale for WHO's new position calling for prompt reporting and public disclosure of interventional clinical trial results. PLoS Med. 2015;12(4):e1001819.

33. The Lancet Editorial Team. 10+ 10: rapid decisions and fast track publication for RCTs. Lancet. 2015;385(9968):578.

34. Button KS, Bal L, Clark A, Shipley T. Preventing the ends from justifying the means: withholding results to address publication bias in peer-review. BMC Psychol. 2016;4(1):59.

35. Kupferschmidt K. Preprints bring 'firehose' of outbreak data. Science. 2020; 367(6481):963-4.

36. Johansson MA, Saderi D. Open peer-review platform for COVID-19 preprints. Nature. 2020;579(7797):29.

37. The MIT Press and UC Berkeley launch rapid reviews: COVID-19 2020 [updated June 29 2020]. Available from: https://rapidreviewscovid19. mitpress.mit.edu/pub/press-release.

38. Zambon M. Developments in the treatment of severe influenza: lessons from the pandemic of 2009 and new prospects for therapy. Curr Opin Infect Dis. 2014;27(6):560-5.

39. DeAngelis CD, Drazen JM, Frizelle FA, Haug C, Hoey J, Horton R, et al. Clinical trial registration: a statement from the International Committee of Medical Journal Editors. JAMA. 2004;292(11):1363-4.

\section{Publisher's Note}

Springer Nature remains neutral with regard to jurisdictional claims in published maps and institutional affiliations.

\section{Ready to submit your research? Choose BMC and benefit from:}

- fast, convenient online submission

- thorough peer review by experienced researchers in your field

- rapid publication on acceptance

- support for research data, including large and complex data types

- gold Open Access which fosters wider collaboration and increased citations

- maximum visibility for your research: over $100 \mathrm{M}$ website views per year

At BMC, research is always in progress.

Learn more biomedcentral.com/submissions 